\title{
Calibration and validation of a dynamic water model in agricultural scenarios
}

\author{
Alfonso Infantino ${ }^{\mathrm{a}}$, Teresa Pereira ${ }^{\mathrm{b}}$, Claudia Ferrari ${ }^{\mathrm{a}}$, Maria José Cerejeira ${ }^{\mathrm{b}}$, \\ Antonio Di Guardo ${ }^{\mathrm{a}, *}$ \\ a Department of Chemical and Environmental Sciences, University of Insubria, Via Valleggio, 11, 22100 Como CO, Italy \\ ${ }^{\mathrm{b}}$ Instituto Superior de Agronomia, Technical University of Lisbon, Tapada da Ajuda, 1349-017 Lisbon, Portugal
}

Received 15 April 2007; received in revised form 16 July 2007; accepted 20 July 2007

Available online 31 August 2007

\begin{abstract}
A dynamic aquatic model (DynA model) was previously developed to predict the fate of a chemical in aquatic scenarios characterized by daily or periodic changes in several input parameters. DynA model is here calibrated with data obtained from the literature in specific unsteady state scenarios, such as those of rice fields. The results obtained for two herbicides (cinosulfuron and pretilachlor) in rice paddy scenarios revealed the capability of the model to accurately predict water and sediment concentrations, as shown by some statistical indicators. Modelling efficiency (EF) values of 0.86-0.99 for the water compartment and of 0.77-0.84 for sediment show the good agreement between predicted and measured concentrations. An "external validation" was performed using measured data for a different herbicide (molinate) applied in a Portuguese paddy rice scenario. A sensitivity analysis for this volatile chemical revealed the influence of some climatic parameters (e.g. temperature) to the model outcomes, such as water and sediment concentrations. This confirmed the capability of DynA model as an efficient tool for the pesticide risk assessment in dynamic scenarios.
\end{abstract}

(C) 2007 Elsevier Ltd. All rights reserved.

Keywords: DynA model; Surface water model; Calibration; Sensitivity analysis; Paddy rice

\section{Introduction}

Existing water - sediment mass balance models are tools for evaluating the mechanisms responsible for contaminant levels and to describe trends in these two compartments (Mackay et al., 1983; Inao and Kitamura, 1999; Mackay, 2001; Capri and Miao, 2002). Most surface water models have been applied in steady-state conditions, in which chemical and environmental properties remain constant during simulation time (Freitas et al., 1997; Lun et al., 1998; Southwood et al., 1999). In situations for which environmental specific data are not well known, a traditional steady-state mass balance model can be employed to predict the order of magnitude of concentrations, especially

\footnotetext{
${ }^{*}$ Corresponding author. Tel.: +39031 2386480; fax: +39031 2386449.

E-mail address: antonio.diguardo@uninsubria.it (A. Di Guardo).
}

when the input of chemical does not change with time. However, this approach can be inappropriate when the scenario is characterized by daily or seasonal variations of some input parameters, including discharge.

An example of this type of behaviour is the pesticide application in rice paddies, where the pesticide environmental fate can be influenced by different applications, rain events, and temperature fluctuations (Cerejeira et al., 2003; Silva et al., 2006). Water balance components (rain, irrigation, drainage, runoff, percolation and evapotranspiration) and their variation with time could be very important in defining pesticide fate. In rice paddies, pesticides are usually applied once or twice during the cultivation period and a common procedure is to hold water for a few days after application; this is necessary for persistence of effect and for prevention of surface water contamination (Inao et al., 2001). Water management is a fundamental process for rice growth and water level in rice paddy varies 
according to pesticide applications and crop requirements. As shown in previous studies, the increase of water holding period after the application reduces the pesticide concentrations in water runoff ( $\mathrm{Vu}$ et al., 2006; Watanabe et al., 2006). Watanabe et al. (2006, 2007), using a modelling approach (PCPF-1 model), compared the influence of different water management scenarios on pesticide behaviour. The results underlined the importance of water management during the earlier period after application, in order to prevent herbicide runoff from rice field, excluding the continuous irrigation scheme from best management practice. Another mathematical model (Wu et al., 2001) was developed in order to assess long term effects of paddy field on the groundwater recharge. Because of these events a paddy field may be considered as a "fully dynamic system" in which parameters such as water volume, water inflow and outflow, chemical application may vary with time.

Several studies on paddy fields have shown that simulation models represent a useful tool to analyze the mechanisms of pesticide transport phenomena and to evaluate the best management practices in controlling pesticides discharges (Inao and Kitamura, 1999; Watanabe and Takagi, 2000a,b; Inao et al., 2001; Capri and Miao, 2002; Watanabe et al., 2006). PADDY (Inao and Kitamura, 1999) is a model used to predict pesticide concentrations in water and sediment and focused particularly on granule formulation of many herbicides. It was initially presented in a steady-state version in which a water balance and weather conditions were not considered; PADDY was later modified including a calculation of a water balance with site-specific conditions.

RICEWQ is another model developed to calculate pesticide dissipation and exposure in rice paddies. This model was tested under European conditions, showing a high agreement between observed and predicted pesticide concentrations in both paddy water and sediment (Capri and Miao, 2002; Karpouzas et al., 2005). RICEWQ accounts for different degradation processes (hydrolysis, photolysis, and microbial degradation) and simulates an accurate water management. Moreover, RICEWQ was coupled to a vadose zone flow and transport model (VADOFT) to consider the fate of pesticide in the underlying soil layers (Miao et al., 2003). PCPF-1 is pesticide fate model validated in Japan paddy field conditions, including water and mass balance pesticide in water and sediment. The water mass balance takes in account different hydrological processes, such as rainfall, irrigation rate, seepage, overflow rate, vertical percolation and evapotranspiration rate. Among the dissipation processes in water, this model also considers photochemical and biochemical degradation (Watanabe et al., 2006). Another rice paddy model is SWAGW, which calculates PEC in surface water, groundwater and paddy soil. A limitation of this model is the lack of hydrological parameter variation during the simulation and lack of the input meteorological data (precipitation, evapotranspiration, and water depth fluctuations) (Karpouzas et al., 2006).
In a previous work, a dynamic aquatic model (Dyna model) (Di Guardo et al., 2006) was developed and illustrated using the DDT contamination of Lake Maggiore scenario in the attempt of estimate approximate emissions. It may be defined as a "highly dynamic model" because of its capability to simulate the daily changes of many parameters (temperature, water inflow and outflow, water volume) of the selected scenario. The objective of this paper is to calibrate and validate DynA model using rice paddy scenarios from the literature (Ferrero et al., 2001; Vidotto et al., 2004) and from an experimental site located in the south of Portugal, for which concentrations were measured (Pereira, 2003).

\section{Materials and methods}

\subsection{Model description}

DynA model is a modelling tool which considers two different compartments, water and sediment, and it is able to predict the fate of a chemical discharged into the system or deriving from inflow water. Dyna model was developed on the grounds of the QWASI Lake Model (Mackay et al., 1983), being a fugacity-based model. In contrast with the original QWASI model, DynA model is dynamic not only in terms of chemical discharge, but also in terms of daily or seasonally variations of some environmental parameters. More specifically, it requires as input data daily values of parameters such as temperature, water inflow and outflow, and water volume. In addition, DynA model allows simulating a discontinuous application of chemicals, a condition that may be represented, for example, by a single spill in a lake or by a pesticide application in a rice paddy. Simulation results are shown in terms of fugacity and concentrations. Fugacity $(f)$ is defined as the tendency of a chemical to escape from a phase, and it is expressed in pressure unit (Pa). The concentration $C\left(\mathrm{~mol} \mathrm{~m}^{-3}\right)$ can be calculated by the following formula:

$C=Z \times f$

where $Z\left(\mathrm{~mol} \mathrm{~m}^{-3} \mathrm{~Pa}^{-1}\right)$ represents the "fugacity capacity", which is specific for each phase (Mackay, 2001). DynA model can simulate the effects of periodic temperature changes on the distribution of pesticide in environmental system. This dependence was considered for vapour pressure, solubility, Henry's law constant, fugacity capacity for water, water column particles and sediment compartments ( $Z$ values), and volatilization. In addition, the model considers the variation of water depth, as well as water flux inflow and outflow. Additional details regarding the model formulation are available in Di Guardo et al. (2006).

\subsection{Calibration scenario}

For model calibration, the rice paddy scenarios from Ferrero et al. (2001) and Vidotto et al. (2004) were selected. 
Table 1

Selected physical chemical properties, half-lives and application rates required by the DynA model

\begin{tabular}{llll}
\hline Property & Cinosulfuron & Pretilachlor & Molinate \\
\hline Molecular weight $\left(\mathrm{g} \mathrm{mol}^{-1}\right)$ & $413.4^{\mathrm{a}}$ & $311.9^{\mathrm{a}}$ & $187.3^{\mathrm{e}}$ \\
Melting point $\left({ }^{\circ} \mathrm{C}\right)$ & $127^{\mathrm{a}}$ & $135^{\mathrm{a}}$ & $25^{\mathrm{e}}$ \\
Water solubility $\left(\mathrm{mg} \mathrm{l}^{-1}\right)$ & $4000^{\mathrm{a}}$ & $50^{\mathrm{a}}$ & $970^{\mathrm{e}}$ \\
Vapour pressure $(\mathrm{Pa})$ & $0.00001^{\mathrm{a}}$ & $0.000133^{\mathrm{a}}$ & $0.75^{\mathrm{e}}$ \\
Kd $\left(1 \mathrm{~kg}^{-1}\right)$ & $1.495^{\mathrm{b}}$ & $7.05^{\mathrm{b}}$ & $5.6^{\mathrm{f}}$ \\
Half-life in water (h) & $468^{\mathrm{b}}$ & $163^{\mathrm{b}}$ & $875.55^{\mathrm{g}}$ \\
Half-life in sediment (h) & $480^{\mathrm{b}}$ & $240^{\mathrm{b}}$ & $978.56^{\mathrm{g}}$ \\
Application rate $\left(\mathrm{kg} \mathrm{a.i.} \mathrm{ha}{ }^{-1}\right)$ & $0.07^{\mathrm{c}}$ & $1.125^{\mathrm{d}}$ & $5.25^{\mathrm{h}}$ \\
\hline${ }^{\mathrm{a}}$ Tomlin (1997). & & \\
b Karpouzas et al. (2006). & & & \\
c Ferrero et al. (2001). & & \\
d Vidotto et al. (2004). & & \\
e Mackay et al. (1997). & & \\
f Calculated by the Dyna model using a log $K_{\text {ow }}$ of 2.88 (Tomlin, 1997). \\
g Inao et al. (2001). \\
h This work.
\end{tabular}

The chemicals considered were cinosulfuron, a sulfonylurea herbicide, and pretilachlor, a chloroacetanilide herbicide. Table 1 shows the physical-chemical properties and application rates for cinosulfuron and pretilachlor utilized in the calibration part, and for molinate in the following "validation" part.

In these papers, data from two different sampling periods in 1997 and 2001, respectively, for cinosulfuron and pretilachlor, were reported; both measured datasets were used for the comparison of predicted and measured values. In particular, measured concentrations are from a test paddy of 2.16 ha within the study area. For each year, triplicate water and sediment samples, (east, west, center sample) were taken.

In 1997, the sampling period started on the 24th of April (day 1) and was completed after 64 days. During this period water flow was stopped three times; the holding periods were from day 1 to 14 , from day 22 to 30 and from 52 to 57 no inflow or outflow of water was present. Cinosulfuron was applied on day 1 and water level was $16 \mathrm{~cm}$. In 2001, pretilachlor was applied on the 5th of April when the water level in the test paddy was $12 \mathrm{~cm}$. After the application the water flow was halted for 23 days. For the simulations, daily information is required, therefore a "daily input scenario" must be defined. Water inflow and water outflow were calculated using the water balance equation presented in Ferrero et al. (2001). Moreover, the following assumption was made in order to obtain a "complete application scenario": daily inlet cinosulfuron concentrations were considered equal to the difference between the highest and lowest values of the considered post holding period. In addition, mean water temperatures were used in the simulation in absence of more specific data.

\subsection{Model parameterization}

DynA model was parameterized using experimental measurements reported in the literature. Paddy field prop- erties and intermedia parameters are summarized in Table 2 , according to the experimental data available (Inao and Kitamura, 1999; Ferrero et al., 2001; Vidotto et al., 2004). Sediment active layer depth was set to $5 \mathrm{~cm}$ for comparison with RICEWQ, SWAGW and PCPF-1 simulation (Karpouzas et al., 2006b). Paddy water depth variation was calculated according to the water balance equation reported in Ferrero et al. (2001). For cinosulfuron and pretilachlor, degradation half-lives in water were derived from the experimental data in Ferrero et al. (2001) and Vidotto et al. (2004). Half-lives in sediment were calculated from $\mathrm{DT}_{50}$ values reported in the literature, assuming first-order decay as reported in Karpouzas et al. (2006b) (Table 1). It is important to note that DynA model does not consider either pesticide decay rate in rice foliage nor crop interception, since a vegetation compartment is not included. In order to calculate temperature variation of solubility and vapour pressure, delta heat of solubilization and delta heat of vaporization were necessary. During calibration, delta heat of solubilization was set to $10 \mathrm{~kJ} \mathrm{~mol}^{-1}$, a default value used in the ChemCAN model (Mackay et al., 1996a,b). In the modeling calibration and "validation" exercises, the delta heats of vaporization for cinosulfuron, pretilachlor and molinate were estimated according to the following empirical relationship (Goss and Schwarzenbach, 1999).

$\Delta H_{\text {vap }}\left(\mathrm{kJ} \mathrm{mol}^{-1}\right)=-3.82 \times \log (\mathrm{VP})+70$

where $\Delta H_{\text {vap }}$ is the enthalpy of vaporization and VP is vapour pressure $(\mathrm{Pa})$ at $25^{\circ} \mathrm{C}$. The calculated values were 114,104 and $71.1 \mathrm{~kJ} \mathrm{~mol}^{-1}$, respectively.

\subsection{Model performance}

Model performance was assessed by comparing predicted values against observed data of cinosulfuron and pretilachlor in paddy water and sediment. In addition, two statistical indices, modelling efficiency (EF) and root mean square error (RMSE), were used to express the overall fit of the model simulation and to compare DynA model to existing rice model results (RICEWQ, SWAGW and PCPF-1), which were applied to the same scenarios (Capri and Miao, 2002; Karpouzas et al., 2005, 2006b). A high EF (close to 1) and low RMSE underline the goodness of the agreement between measured and predicted data. The following Eqs. (3) and (4) report EF and RMSE calculation:

$\mathrm{EF}=\frac{\sum(O-\bar{O})^{2}-\sum(P-O)^{2}}{\sum(O-\bar{O})^{2}}$
$\mathrm{RMSE}=\frac{100}{\bar{O}} \sqrt{\frac{\sum_{i=1}^{n}\left(P_{i}-O_{i}\right)^{2}}{n}}$

where $O$ is measured value, $\bar{O}$ is the average of measured values, $P$ is predicted value and $n$ is the number of observations. 
Table 2

Paddy field properties in the calibration and validation scenarios

\begin{tabular}{|c|c|c|c|}
\hline Property & Calibration scenario & & Validation scenario \\
\hline Water surface area $\left(\mathrm{m}^{2}\right)$ & $21600^{\mathrm{a}}$ & & 24000 \\
\hline Sediment active layer depth $(\mathrm{m})$ & & $0.05^{\mathrm{b}}$ & \\
\hline Concentration of particles in water column $\left(\mathrm{mg} \mathrm{l}^{-1}\right)$ & & $45^{\mathrm{b}}$ & \\
\hline Concentration of particles in inflow water $\left(\mathrm{mg} \mathrm{l}^{-1}\right)$ & & $45^{\mathrm{g}}$ & \\
\hline Density of particles in water $\left(\mathrm{kg} \mathrm{m}^{-3}\right)$ & & $2400^{\mathrm{c}}$ & \\
\hline Density of particles in sediment $\left(\mathrm{kg} \mathrm{m}^{-3}\right)$ & & $2400^{\mathrm{c}}$ & \\
\hline Density of aerosol particles $\left(\mathrm{kg} \mathrm{m}^{-3}\right)$ & & $1500^{\mathrm{c}}$ & \\
\hline Fraction of organic carbon in water column particles & & $0.2^{\mathrm{d}}$ & \\
\hline Fraction of organic carbon in sediment solid particles & $0.013^{\mathrm{a}}$ & & 0.018 \\
\hline Fraction of organic carbon in resuspended sediment particles & $0.013^{\mathrm{h}}$ & & 0.018 \\
\hline Fraction OC in inflow suspended sediment solids & $0.013^{\mathrm{h}}$ & & 0.018 \\
\hline Rain rate $\left(\mathrm{m} \mathrm{y}^{-1}\right)$ & $0.935^{\mathrm{a}}$ & & 0.865 \\
\hline Aerosol dry deposition velocity $\left(\mathrm{m} \mathrm{h}^{-1}\right)$ & & $7.2^{\mathrm{c}}$ & \\
\hline Scavenging ratio & & $200000^{\mathrm{c}}$ & \\
\hline Volatilization MTC (air side) $\left(\mathrm{m} \mathrm{h}^{-1}\right)$ (MTCa) & & $5^{\mathrm{c}}$ & \\
\hline Volatilization MTC (water side) $\left(\mathrm{m} \mathrm{h}^{-1}\right)$ & & $0.05^{\mathrm{c}}$ & \\
\hline Burial rate of solids $\left(\mathrm{g} \mathrm{m}^{-2} \mathrm{day}^{-1}\right)$ & & $0.95^{\mathrm{d}}$ & \\
\hline Resuspension rate of solids $\left(\mathrm{g} \mathrm{m}^{-2} \mathrm{day}^{-1}\right)$ & & $0.22^{\mathrm{d}}$ & \\
\hline Deposition rate of solids $\left(\mathrm{g} \mathrm{m}^{-2} \mathrm{day}^{-1}\right)$ & & $1.217^{\mathrm{d}}$ & \\
\hline Sediment - water diffusion MTC $\left(\mathrm{m} \mathrm{h}^{-1}\right)$ (MTCws) & & $0.0002^{\mathrm{e}}$ & \\
\hline Volume fraction of particles in surface sediment & & $0.6^{\mathrm{f}}$ & \\
\hline
\end{tabular}

${ }^{\mathrm{a}}$ Ferrero et al. (2001).

b Capri and Miao (2002).

c Mackay (2001).

d Mackay et al. (1994).

e MacLeod et al. (2002).

${ }^{\mathrm{f}}$ Inao and Kitamura (1999).

g Assumed as the same concentration of the water column.

${ }^{\mathrm{h}}$ Assumed as the same value of OC fraction in sediment particles.

\subsection{Validation scenario: site details and measurements}

Rice is one of the main Portuguese irrigated crops. According to FAO (2002) during 2001 this crop occupied about 24000 ha, mainly distributed along three agricultural regions: Mondego Valley, Tagus Valley and Sado Valley. Among these three regions "Low Sado Valley" was chosen as study area; it is an intensive agricultural region located in the South of Portugal, near "Alcácer do Sal" city. In this region rice is the main culture and it covers about 5000 ha; other crops are maize (150 ha), orchard (90 ha), sorghum (30 ha), tomato (18 ha), other (23 ha).

A "test rice paddy" of 2.4 ha was selected to perform this study. The soil texture was silty clay (clay $57.1 \%$, silt $34.2 \%$, sand $8.7 \%$ ) and it was characterized by $1.8 \%$ organic carbon, soil $\mathrm{pH}$ of 6.2 , hydraulic conductivity at saturation of $0.5 \mathrm{~mm} \mathrm{day}^{-1}$ (Pereira, 2003) and a bulk density for dry soil of $1.3 \mathrm{~kg} \mathrm{l}^{-1}$ (both measured at $0.15 \mathrm{~m}$ depth).

\subsection{Pesticide application and water sampling}

Molinate was applied by plane under flooded conditions $(11 \mathrm{~cm}$ average water level) in the experimental paddy on the 31st of May 2000. The formulation used was the granular "Ordram ${ }^{\circledR}$ granulado" (Aventis) with $7.5 \%$ of active ingredient at the dose of $70 \mathrm{~kg} \mathrm{ha}^{-1}$ of the commercial product. Water samples for the pesticide quantification

were collected using a $200 \mathrm{ml}$ glass vessel at five sampling sites, selected in order to be the most representative of the possible existing sub-points, such as water entrances, water exits and center of the paddy.

Sowing occurred at 31st of May and was performed by plane in a flooded paddy. Rice variety was "Gládio". Besides molinate, endosulfan (Thionex ${ }^{\circledR} ; \mathrm{EC}$ ) was applied for Chironomus spp. control, at a rate of $0.51 \mathrm{ha}^{-1}$, in a flooded paddy (4th of July) and a mixture of the herbicides propanil + MCPA + quinclorac $\quad\left(\right.$ Orizerba $^{\circledR}+$ Printormona $^{\circledR}+$ Facet $\left.^{\circledR}\right)$, at a rate of $121 \mathrm{ha}^{-1}+1.21 \mathrm{ha}^{-1}+$ $21 \mathrm{ha}^{-1}$, respectively, by plane in an un-flooded paddy (11th of July). The final sample (11) was composed by the five sub-samples. The sampling frequency was established according to the time of pesticide application. Water samples were collected just before and 0 (immediately after application), 2, 5, 7, 9, 12, 14, 19, 21, 26 and 28 days after application. Each sample was immediately chilled and transported to the laboratory for analysis. Simultaneously to sampling, field measurements of water level, $\mathrm{pH}$, temperature, oxygen and electric conductivity (EC) were performed (Pereira, 2003).

\subsection{Pesticide analysis: $S P M E$ and $G C-M S$ analysis}

At the laboratory, water samples were stored in the dark and kept at $4{ }^{\circ} \mathrm{C}$ until analysis. All the samples were filtered with $0.45 \mu \mathrm{m}$ glass fiber filters in order to determine the 
true dissolved chemical concentration. Molinate was analyzed using solid-phase microextraction (SPME) technique. The fiber coatings used were $85 \mu \mathrm{m}$ polyacrylate. Extraction conditions were the following: 60 min immersion with salt (saturation); $\mathrm{pH}$ adjusted to 2; magnetic stirring rate at $600 \mathrm{rpm}$. Desorption time was $10 \mathrm{~min}$. Mass Spectrometric analysis was performed with a Varian ChromPack CP-3800 Gas Chromatograph coupled to a Varian (Walnut Creek, USA) Saturn 2000 GC/MS equipped with an Ion Trap detector. A J\&W (Folfom, USA) DB-5 MS $30 \mathrm{~m} \times$ $0.25 \mathrm{~mm} \times 0.25 \mu \mathrm{m}$ Low Bleed/MS column was used. Helium was employed as carrier gas at $83 \mathrm{kPa}$. The injector and mass spectrometric detector temperatures were both $240{ }^{\circ} \mathrm{C}$. The oven temperature was programmed from 70 to $190{ }^{\circ} \mathrm{C}$ at $7{ }^{\circ} \mathrm{C} \mathrm{min}^{-1}$, from 190 to $220^{\circ} \mathrm{C}$ at $5^{\circ} \mathrm{C} \mathrm{min}^{-1}$, from $220^{\circ} \mathrm{C}$ to $240^{\circ} \mathrm{C}$ at $15^{\circ} \mathrm{C} \mathrm{min}{ }^{-1}$, with a final isotherm of $4 \mathrm{~min}$. Ionization mode was electronic impact (EI) in full scan between 70 and $350 \mathrm{mz}^{-1}$. The ions used for identification and quantification were $98+126$. The detection limit for molinate was $20 \mathrm{ng} \mathrm{l}^{-1}$.

\subsection{Sensitivity analysis}

In the validation scenario, two types of sensitivity analysis were performed in order to evaluate the sensitivity of predicted molinate water and sediment concentration in paddy field. The first analysis was done to describe the influence of environmental parameters, such as water temperature and compartment volumes, on concentration trends. For this reason, six different scenarios were compared using the EF and RMSE statistical indicators to evaluate observed and predicted water concentrations. Each one of these scenarios was characterized by different dynamic conditions, ranging from constant to highly dynamic situation. The default situation is represented by the F scenario, in which temperature and water depth change during the simulation, and water input and output fluxes are present. Scenario A is characterized by average temperature and average water depth; scenario B is characterized by average temperature and water depth variation; scenario $\mathrm{C}$ is characterized by temperature variation and average water depth. Finally, scenario $\mathrm{D}$ and $\mathrm{E}$ were respectively the same as scenario $\mathrm{C}$ and $B$ with in addition water inflow and outflow.

In the second type of sensitivity analysis, four input parameters were identified as the most sensitive and selected: the air side mass transfer coefficient (MTCa), the water-sediment mass transfer coefficient (MTCws), the half-life in water (HLW), and the delta heat of vaporization (DHV). These input parameters were preliminarily identified as uncertain variables, because they were characterized by the highest uncertainty according to previous modelling studies (Meyer et al., 2005). A variability of $\pm 50 \%$ of the default value, reported in Table 2 , was assigned to each parameter. Thus, additional simulations were conducted to evaluate the influence of input parameter variation on water paddy concentrations, during the sampling period.

\section{Results and discussion}

\subsection{Model calibration}

Fig. 1 shows the measured concentration in water and sediment compared to the DynA model simulation results; the average values for the measured results derive from concentrations measured in three different sampling sites (west, east and centre) (Ferrero et al., 2001; Vidotto et al., 2004). Table 3 reports the statistical performance indices, EF and RMSE, for cinosulfuron and pretilachlor scenarios, which will be discussed later. A limited calibration for water-sediment diffusion parameter (MTCws) was performed against observed data, in order to identify the value providing the best fit for the paddy rice scenarios. The MTCws parameter was previously identified among the input parameters with highest uncertainty (MacLeod et al., 2002). The statistical indicators underlined that the best fit was obtained when MTCws was set to $1.5 \times 10^{-4} \mathrm{~m} \mathrm{~h}^{-1}$. When the default value $\left(2 \times 10^{-4} \mathrm{~m} \mathrm{~h}^{-1}\right)$ was used, the model did not accurately predict the sediment concentration trend for both chemicals, as shown by the low EF values ( 0.58 and 0.51 , respectively). In fact, a variation of $25 \%$ of MTCws value produced a significant increase of modelling efficiency (EF) $(0.844$ and 0.77 , respectively). The selected value for MTCws did not significantly change the model performance $(\mathrm{EF}$ variation $<2 \%$ ) for paddy water concentration prediction. Therefore, this value was used for the following calibration attempts.

\subsubsection{Cinosulfuron scenario}

Fig. 1a shows a general agreement between observed and predicted concentrations under calibrated conditions. This was further supported by a high statistical indicator EF value for water (0.86) and sediment (0.84), which is comparable to the calibrated RICEWQ results $(\mathrm{EF}=0.91$ and 0.87 , respectively) and satisfactory low RMSE value for each media (44.8 in water and 30 in sediment), which are the best results among the models tested. Dyna model slightly overpredicted the average concentrations in water, between 0 and 14 DAT, during the paddy closure time. In Capri and Miao (2002), RICEWQ initial predictions overestimated measured results between 0 DAT and 8 DAT, and this was ascribed to the consideration of a $100 \%$ efficiency of application, not evaluating volatilization, drift and losses during formulate application. In the RICEWQ calibration the authors found a good agreement between observed and predicted concentrations, using measured initial concentration in paddy water in place of application dose. A similar dissipation trend in water reported in Fig. 1 was found for RICEWQ and PCPF-1 simulations, as shown in Karpouzas et al. (2006b), in which the dissipation pattern during paddy closure (0-14 DAT, 22-30 DAT and 52-57 DAT) was attributed to a high evaporation of paddy water, contributing to a gradual concentration of the chemical in the remaining water. Therefore, when the dynamic water management is used in the DynA model 

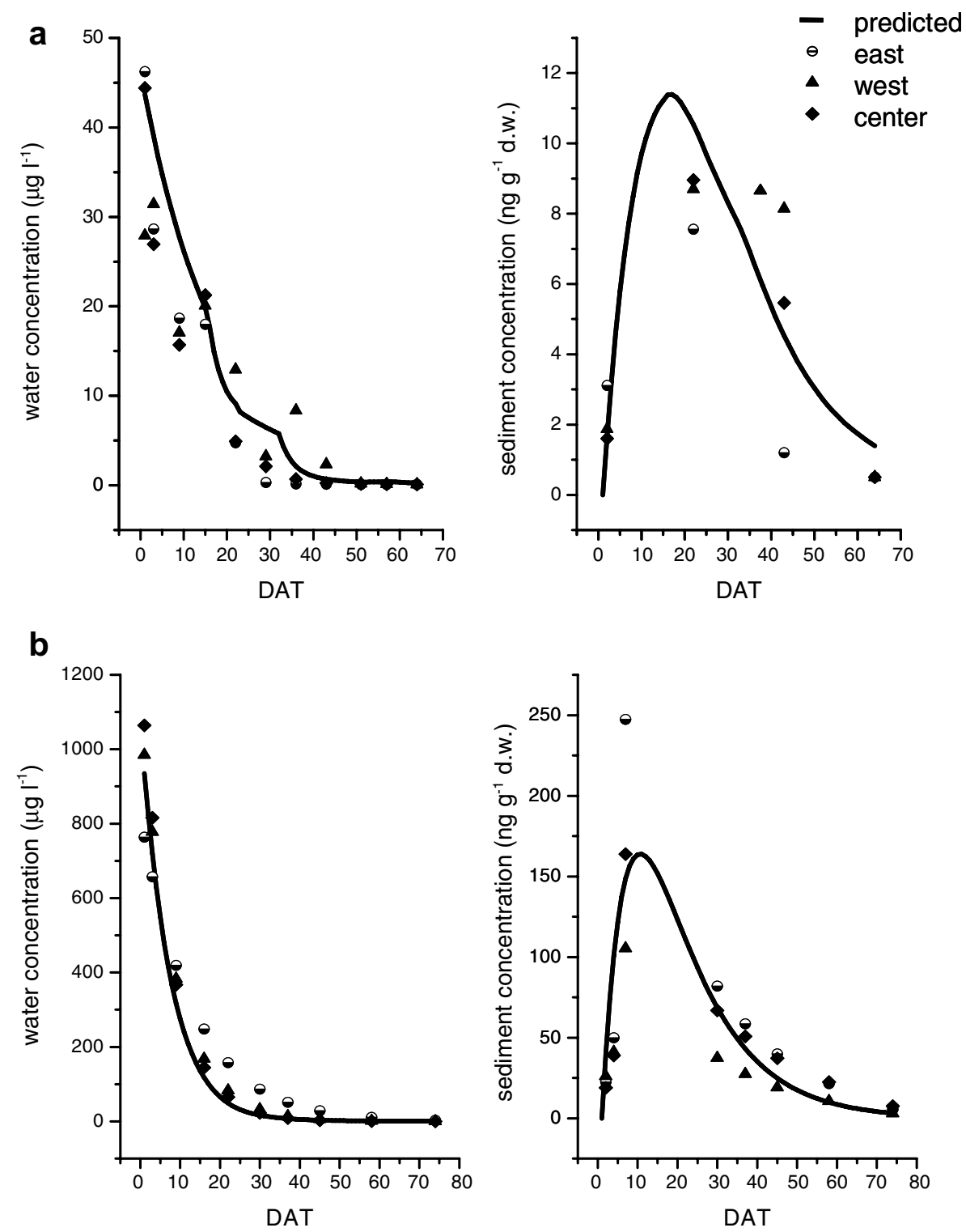

Fig. 1. Measured and predicted concentrations in water $\left(\mu \mathrm{g} \mathrm{l}^{-1}\right)$ and in sediment ( $\mathrm{ng} \mathrm{g}^{-1}$ d.w.) for cinosulfuron (a) and pretilachlor (b).

Table 3

Comparison of EF and RMSE for DynA model and other rice models

\begin{tabular}{llllll}
\hline Models & \multicolumn{2}{l}{ Cinosulfuron } & & Pretilachlor & \\
\cline { 2 - 3 } \cline { 5 - 6 } & Water & Sediment & & Water & Sediment \\
\hline EF value & & & & & \\
DynA model & $0.88 / 0.86^{\mathrm{b}}$ & $0.58 / 0.84^{\mathrm{b}}$ & & $0.977 / 0.985^{\mathrm{b}}$ & $0.51 / 0.77^{\mathrm{b}}$ \\
RICEWQ & $0.81^{\mathrm{a}} / 0.91^{\mathrm{c}}$ & $0.891^{\mathrm{a}} / 0.87^{\mathrm{c}}$ & & $0.905^{\mathrm{a}} / 0.935^{\mathrm{d}}$ & $0.508^{\mathrm{a}} / 0.702^{\mathrm{d}}$ \\
SWAGW & $0.253^{\mathrm{a}}$ & $0.112^{\mathrm{a}}$ & & $0.791^{\mathrm{a}}$ & $0.273^{\mathrm{a}}$ \\
PCPF-1 & $0.482^{\mathrm{a}}$ & $0.868^{\mathrm{a}}$ & & $0.993^{\mathrm{a}}$ & $0.021^{\mathrm{a}}$ \\
RMSE value & & & & & \\
DynA model & $41.6 / 44.8^{\mathrm{b}}$ & $48 / 30^{\mathrm{b}}$ & & $20 / 15.8^{\mathrm{b}}$ & $68 / 46.5^{\mathrm{b}}$ \\
RICEWQ & $52.6^{\mathrm{a}} / 37^{\mathrm{c}}$ & $29.5^{\mathrm{a}} / 27^{\mathrm{c}}$ & & $42.3^{\mathrm{a}} / 35^{\mathrm{d}}$ & $87^{\mathrm{a}} / 67.7^{\mathrm{d}}$ \\
SWAGW & $104.2^{\mathrm{a}}$ & $115.2^{\mathrm{a}}$ & & $62.8^{\mathrm{a}}$ & $144.9^{\mathrm{a}}$ \\
PCPF-1 & $86.8^{\mathrm{a}}$ & $32.1^{\mathrm{a}}$ & & $11.5^{\mathrm{a}}$ & $122.7^{\mathrm{a}}$ \\
\hline
\end{tabular}

${ }^{a}$ Data adapted from Karpouzas et al. (2006b).

${ }^{\mathrm{b}}$ Calibrated as explained in 3.1.

c Calibrated model results (Capri and Miao, 2002).

${ }^{\mathrm{d}}$ Calibrated results (Karpouzas et al., 2005). performance increases, as well as for RICEWQ and PCPF-1 (0.91-0.482), compared to the SWAGW model $(\mathrm{EF}=$ 0.253 ), which assumed a constant paddy water depth during simulation time.

Given the low Kd for cinosulfuron, a limited affinity for the sediment compartment is to be expected. The lowest sediment concentrations were found in the east part of the paddy where the inlet and outlet floodgates were located, showing the effect of desorption due to increased water flux on cinosulfuron concentration (Ferrero et al., 2001). However, the calibrated model showed a good agreement between measured and predicted concentrations in paddy sediment (Fig. 1a). DynA model simulates a dissipation pattern similar to RICEWQ and PCPF-1, as confirmed by the EF values (0.84, 0.87, and 0.868). SWAGW EF value (0.112) is considerably lower and this was attributed to a more rapid partitioning and dissipation trend 
predicted. RMSE index confirmed the same behaviour, with a value equivalent to 30 , which is comparable to the RICEWQ and PCPF-1 results (27 and 32.1).

\subsubsection{Pretilachlor scenario}

In the pretilachlor application (Fig. 1b) the calibrated model well predicted water concentrations, confirmed by the high EF value (0.985) and low RMSE value (15.8), which were among the best results together with those from PCPF-1. EF values for the RICEWQ and SWAGW simulations ranged between 0.791 and 0.935 (Karpouzas et al., 2006b). Pretilachlor dissipation during gate closure is most likely attributable to degradation due to microbial activity (Vidotto et al., 2004), while leaching generally plays a less important role when subsurface flow through macropores is not significant. The model also accurately predicted concentrations in sediment, as shown by the highest EF value (0.77) in comparison to RICEWQ model result (0.702) for the same scenario with calibrated condition (Karpouzas et al., 2005). It is interesting to observe that both models in not calibrated conditions show the same EF value (about $0.50)$. In contrast, SWAGW and PCPF-1 over - or underestimated the sediment concentrations, as illustrated by the lower EF value (0.273 and 0.021) and the higher RMSE value (about 145 and 123), showing a different dissipation pattern compared to DynA and RICEWQ models. In short, both simulations revealed a comparable, if not better, behaviour of DynA model in the calibration scenarios.

\subsection{DynA model validation}

Once the model was calibrated, in order to verify the predictive capability of the model, an external validation was attempted. The "validation" term is to be intended as the practical verification of the capability of the model to obtain results which are close to the measured results in an independent scenario, not utilized to "build" or "calibrate" the model. However, as suggested in Oreskes et al. (1994), a complete validation of the model, given the complexity of the assumptions is not practically possible.

\subsubsection{Paddy water experimental data}

The average $\mathrm{pH}$ and $\mathrm{EC}$ values registered during the year 2000 in the paddy water were 7.2 and $1800\left(\mu \mathrm{S} \mathrm{cm}^{-1}\right)$, respectively. Fig. 2 summarizes the trends of temperature, and water management during the 30 day simulation time. The water temperature range varied from 21 to $36^{\circ} \mathrm{C}$ and the mean value was $27.4^{\circ} \mathrm{C}$. Molinate was applied on May 31st (arrow in Fig. 2). The water depth at application time was $11 \mathrm{~cm}$ and was kept constant for about a week then was lowered to a minimum of about $4 \mathrm{~cm}$. In the sampling period, the mean water depth was $8.5 \mathrm{~cm}$. Floodgates were open in this period as shown in Fig. 2. All available dynamic parameters (temperature, water level, water input and output) were used in the model.

\subsubsection{Application of DynA model in the Portuguese paddy rice scenario}

"DynA model" was applied to the scenario previously described. The chemical selected for the simulation was molinate and its physical-chemical properties are shown in Table 1, while the environmental data required by the model, such as water surface area, fraction of organic carbon, and rain rate etc., are reported in Table 2. Fig. 3 shows predicted concentration calculated by "DynA model" in the default "fully dynamic" scenario (line F)

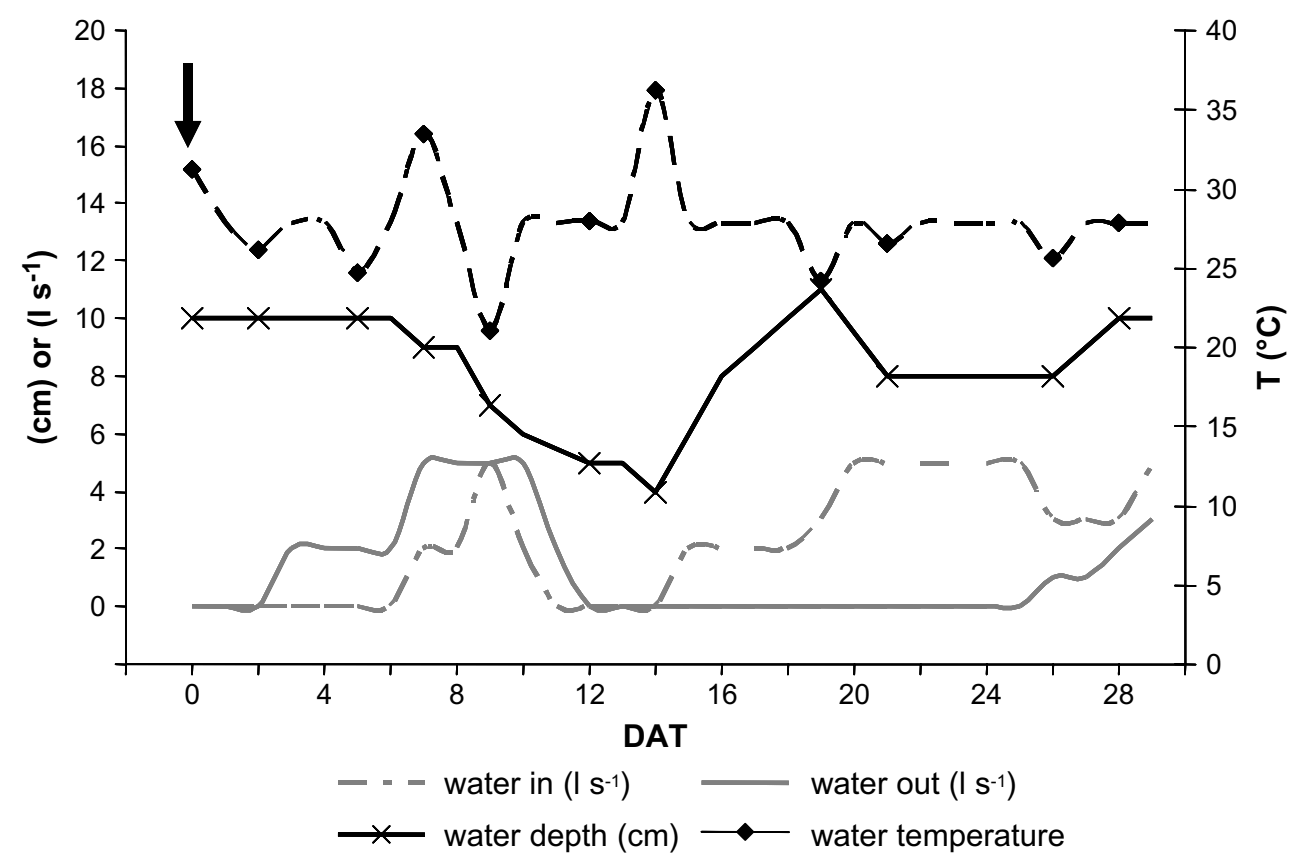

Fig. 2. Daily fluctuations of temperature $\left({ }^{\circ} \mathrm{C}\right)$, water depth $(\mathrm{cm})$, water input and output $\left(1 \mathrm{~s}^{-1}\right)$, and molinate application (arrow) during the sampling period. 

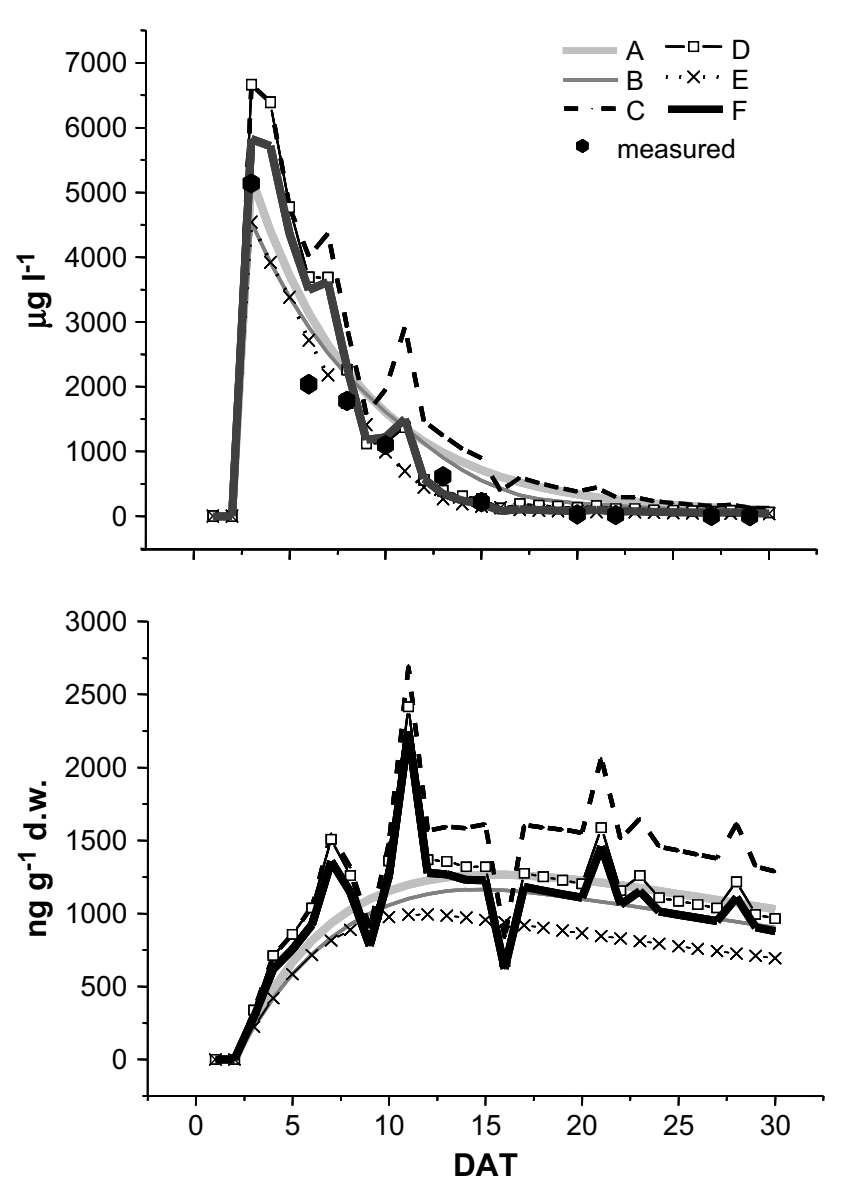

Fig. 3. Results of DynA model simulation in different scenario compared to water experimental concentrations ( $\mu \mathrm{g} 1^{-1}$, graph above) and concentrations in sediment compartment (ng g ${ }^{-1}$ d.w., graph below). (A: average condition scenario; B: only water depth variation; $\mathrm{C}$ : only water temperature variation; D: water temperature variation + water in and out; E: water depth variation + water in and out; F: default "fully" dynamic scenario.)

compared to the measured concentrations in the water compartment, and predicted concentration in sediment. The maximum concentration detected in water was $5140 \mu \mathrm{g}^{-1}$, one day after the application. Molinate dissipation in paddy water can be described by a first-order kinetic model. The calculated $\mathrm{DT}_{50}$ in this compartment was 2.4 days, in agreement with the $\mathrm{DT}_{50}$ value reported from Christen et al. (2006) in the paddy field of South Eastern Australia (2.7 days).

Many paddy models (Karpouzas et al., 2005, 2006a; Christen et al., 2006) use $\mathrm{DT}_{50}$ values to estimate half-life in water then use the half-life in calculation. In certain situations, such as for volatile or many hydrophobic chemicals, this approach could be potentially in error, because it lumps up other loss processes. For DynA model, a laboratory degradation half-life of 36.5 days (corresponding to a degradation rate constant of $0.019 \mathrm{day}^{-1}$ ) was used (Inao and Kitamura, 1999).

This assumption allows a better quantification of the other losses, and in particular the volatilization flux, which is responsible for $75-85 \%$ of the estimated loss for molinate from the paddy system (Soderquist et al., 1977).

As in the calibration scenario, a good agreement between observed and estimated model values in paddy water was observed. This result was confirmed by the high value $\mathrm{EF}(0.87)$ for the water compartment. A similar comparison for the sediment compartment is not possible, given the lack of measured sediment concentrations.

\subsubsection{Sensitivity/uncertainty analysis results}

A dynamic model can be used to evaluate sensitivity/ uncertainty of parameters by comparing parameter distribution. This comparison can give an idea of the expected change in PEC calculation obtainable using more or less dynamic models and allow a quantification of the PEC estimation. Arp et al. (2005) discriminate between natural variability and parameter uncertainty. In sensitivity/ uncertainty analysis, natural variability is associated to the variability of environmental parameters (average or dynamic condition), such as temperature and wind speed, while parameter uncertainty evaluates unknown or uncertain input parameters.

Fig. 3 shows the results for the first sensitivity/uncertainty analysis, in which water and sediment concentration variations are displayed in the six different scenarios $(\mathrm{A} \rightarrow \mathrm{F})$ of Section 2.8. In the water compartment, a better agreement between predicted and measured data was shown in the isothermal scenario (A-B-E), characterized by the highest EF values (0.90-0.92-0.96) and corresponding lowest RMSEs (43-39-28). However, an increase of prediction efficiency was observed in the non-isothermal scenarios, from the simplest to the most dynamic scenario (D-C-F). This evidence was confirmed by the EF values: 0.60 for scenario D and 0.87 for the default scenario $(\mathrm{F})$. Thus, for the water compartment the increase of complexity of the water management description seem to determine the model efficiency, as reported in some previous modelling work (Karpouzas et al., 2006b).

The coupling between temperature variation and water management ( $\mathrm{F}$ scenario) showed a good prediction in the most realistic scenario. The importance of this scenario is well shown in the sediment compartment. Molinate sediment trend was inversely proportional to the water temperature fluctuations. This behaviour can be imputable to a significant temperature effect on the calculated fugacity capacity of the water compartment, as demonstrated by Paraiba et al. (2002), in an illustration of a Level IV Fugacity model for molinate in a similar water system. While the average temperature conditions (scenarios $\mathrm{A}, \mathrm{B}$ and $\mathrm{E}$ ) revealed a smooth behaviour in sediment concentration increase, the most dynamic conditions (scenarios C, D and $\mathrm{F}$ ), in which temperature changed, outlined a more dramatic behaviour with peaks which oscillated of about a factor of 2.5 from the average results.

A more precise comparison of sensitivity of the most influential parameters for water concentration changes can be seen in Fig. 4. The model was run according to 


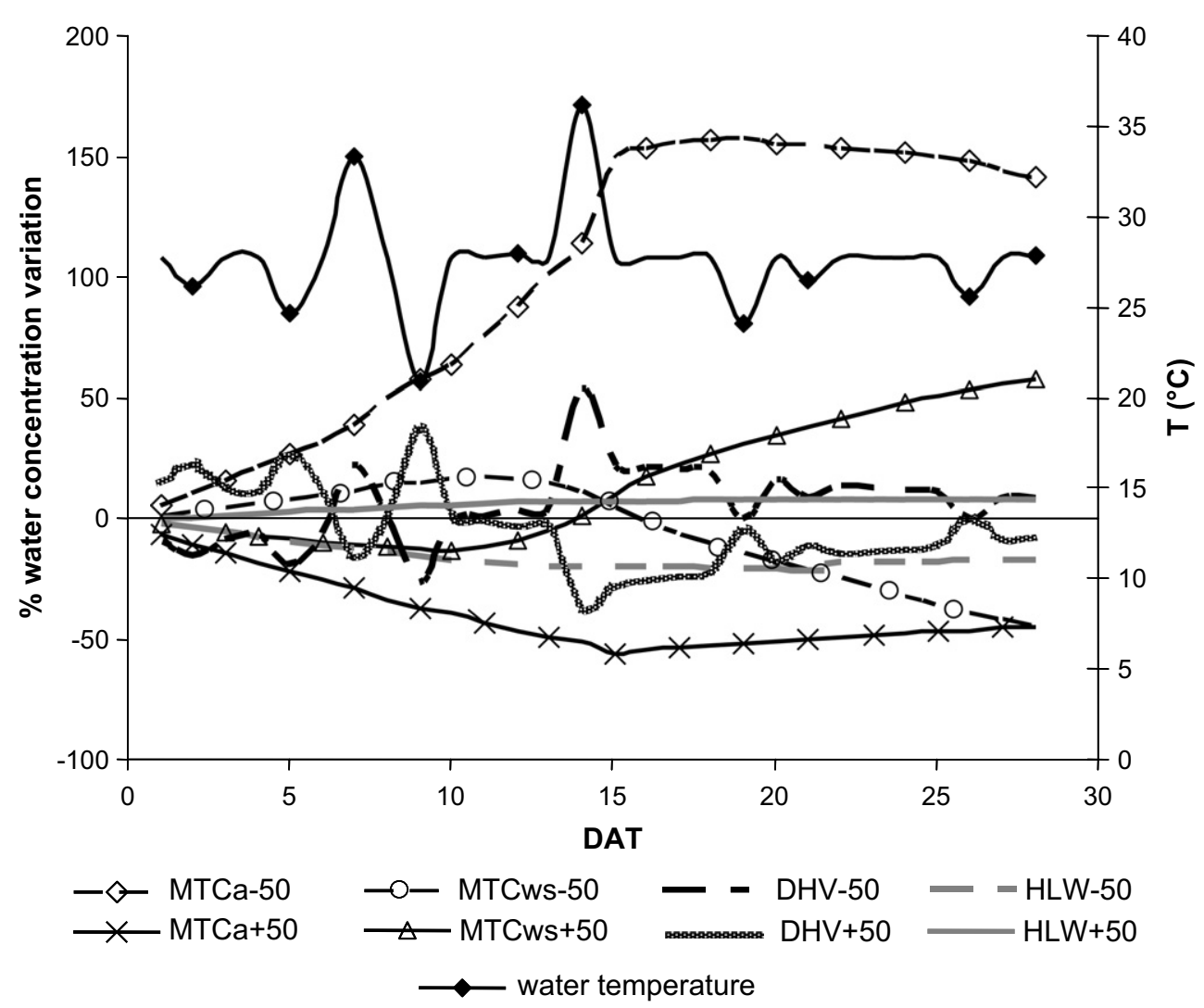

Fig. 4. Sensitivity analysis of DynA model simulation for molinate: percentage of water concentration variation during the simulation time due to the change of the most sensitive input parameters.

the F scenario depicted above, while the air side mass transfer coefficient (MTCa), the water-sediment mass transfer coefficient (MTCws), the half-life in water (HLW) and the delta heat of vaporization (DHV) where changed of $\pm 50 \%$. Variation of temperature was also displayed in the figure for comparison purposes. Water concentrations were reported daily as relative difference from each simulation scenario and the default value. Therefore all variations can be compared for the same date. From Fig. 4, HLW and MTCws appeared as the least sensitive parameters. On the contrary, the parameter which showed the largest capability of changing water concentrations is the MTCa; when MTCa is increased by $50 \%$ (e.g. depending on wind speed increase) the concentrations in water are reduced up to $50 \%$. Similarly, when MTCa is reduced by $50 \%$, water concentrations are increased until DAT 15 . The DHV simulations $( \pm 50 \%)$ showed mirror-image behaviour: for example. an increase of $50 \%$ of the value induced a reduction in water concentration, caused by the increased volatilization, which is in term influenced by the temperature increase. This is the reason why the negative peaks in water concentrations caused by the highest DHV $(+50 \%)$ were correlated to the temperature peaks.

\subsubsection{Predicted volatilization fluxes}

The significance of volatilization for a chemical such as molinate is relative to the potential contamination of other areas and the possible effect on aquatic and terrestrial ecosystem (Cerejeira et al., 2003; Pereira, 2003; Silva et al., 2006). Since the most important loss process for this system was the volatilization flux, an additional calculation was performed to compare the value with the reported literature value at day one after treatment (1 DAT). The importance of the comparison derives from the fact that the volatilization flux and its uncertainty are generally not properly considered in previous models (Seiber et al., 1986). Ferrari et al. (2005) found a significant correlation between Henry's law constant (Hk) and volatilization rate $\left(K_{\mathrm{vol}}\right)$ for some pesticides $\left(K_{\mathrm{vol}}=0.0016 \mathrm{Hk}^{0,3147}, R^{2} 0.91-\right.$ $0.98)$ and introduced a routine to calculate volatilization flux in RICEWQ model. Heald et al. (2005) performed an uncertainty analysis in a volatilization model to evaluate the influence of environmental parameters on water-air mass transfer rate for VOCs, such as daily wind speed and surface water temperature. The estimated mean volatilization flux for molinate in DynA model was about $52 \mathrm{mg} \mathrm{m}^{-2}$ day $^{-1}$, similar to the average value reported by Ross and Sava (1986) (46.32 $\mathrm{mg} \mathrm{m}^{-2}$ day $^{-1}$ ), and of the same order of magnitude of Soderquist et al. (1977).

Considering the range of variation of MTCa and DHV shown in Section 3.2.3, a volatilization flux can be calculated. The flux ranged from 30 to $70 \mathrm{mg} \mathrm{m}^{-2}$ day $^{-1}$, depending on temperature, and this is in accordance with a previous study (Ross and Sava, 1986), in which the var- 
iability of experimental data ranged between 33 and $78 \mathrm{mg} \mathrm{m}^{-2}$ day $^{-1}$.

\section{Conclusions}

DynA model was calibrated and validated in a dynamic rice paddy scenario. The calibration was performed using experimental data from available agricultural scenarios, and showed a very good performance of the DynA model. The model was then validated using the results of a field experiment in a Portuguese rice paddy. The simulations confirmed a good agreement between measured and predicted values. The validation results in the Portuguese scenario showed the similar order of magnitude of volatilization flux between existing measured data and the estimated values from DynA model. Uncertainty analysis permitted to evaluate the different contribution of selected environmental and transport data to the water concentration variability. The main contribution to uncertainty was attributed to the temperature variation, the air side mass transfer coefficient (MTCa) and the delta heat of vaporization (DHV). The results suggested that DynA model can be considered a useful tool for the prediction of chemical concentration in water and sediment in such dynamic ecosystems.

\section{Acknowledgements}

Project MIUR-COFIN 2002 GIS-based assessment and spatial distribution of the ecotoxicological risk deriving by pesticide use is gratefully acknowledged for funding part of this study. The Ph.D. course in "Environmental Sciences" of the University of Insubria is acknowledged for granting a fellowship to A.I.

\section{References}

Arp, H.P.H., Fenner, K., Schmidt, T.C., 2005. Predicting methyl tertbutyl ether, tert-butyl formate, and tert-butyl alcohol levels in the environment using the fugacity approach. Environ. Sci. Technol. 39, 3237-3244.

Capri, E., Miao, Z., 2002. Modelling pesticide fate in rice paddy. Agronomie 22, 363-371.

Cerejeira, M.J., Viana, P., Batista, S., Pereira, T., Silva, E., Valério, M.J., Silva, A.M., Ferreira, M., Silva-Fernandes, A., 2003. Pesticides in Portuguese surface and ground waters. Water Res. 37, 1055-1063.

Christen, E.W., Chung, S., Quayle, W.C., 2006. Simulating the fate of molinate in rice paddies using the RICEWQ model. Agri. Water Manage. 85, 38-46.

Di Guardo, A., Ferrari, C., Infantino, A., 2006. Development of a dynamic aquatic model (DynA Model): Estimating temporal emissions of DDT to Lake Maggiore (N. Italy). Environ. Sci. Pollut. R 13, 5058.

FAO (2002) - FAOSTAT: http://faostat.fao.org/.

Ferrari, F., Karpouzas, D.G., Trevisan, M., Capri, E., 2005. Measuring and predicting environmental concentrations of pesticides in air after application to paddy water systems. Environ. Sci. Technol. 39, 29682975.

Ferrero, A., Vidotto, F., Gennari, M., Nègre, M., 2001. Behavior of cinosulfuron in paddy surface waters, sediments, and ground water. J. Environ. Qual. 30, 131-140.
Freitas, H., Diamond, M., Semkin, R., Gregor, D., 1997. Contaminant fate in High Artic Lakes: development and application of a mass balance model. Sci. Tot. Environ. 201, 171-187.

Goss, K., Schwarzenbach, R.P., 1999. Empirical prediction of heat of vaporization and heat of adsorption of organic compound. Environ. Sci. Technol. 33, 3390-3393.

Heald, P.C., Schladow, S.G., Reuter, J.E., Allen, B.C., 2005. Modeling MTBE and BTEX in lakes and reservoirs used for recreational boating. Environ. Sci. Technol. 39, 1111-1118.

Inao, K., Kitamura, Y., 1999. Pesticide paddy field model (PADDY) for predicting pesticide concentrations in water and soil in paddy field. $\mathbf{J}$. Pestic. Sci. 55, 38-46.

Inao, K., Ishii, Y., Kobara, Y., Kitamura, Y., 2001. Prediction of pesticide behaviour in paddy field by water balance on the water management using pesticide paddy field model (PADDY). J. Pestic. Sci. 26, 229235.

Karpouzas, D.G., Ferrero, A., Vidotto, F., Capri, E., 2005. Application of the RICEWQ-VADOFT model for simulating environmental fate of pretilachlor in rice paddies. Environ. Toxicol. Chem. 24, 10071017.

Karpouzas, D.G., Capri, E., Papadopoulou-Mourkidou, E., 2006a. Basinscale risk assessment in rice paddies: An example based on the Axios river basin in Greece. Vadose Zone J. 5, 273-282.

Karpouzas, D.G., Cervelli, S., Watanabe, H., Capri, E., Ferrero, A., 2006b. Pesticide exposure assessment in rice paddies in Europe: a comparative study of existing mathematical models. Pest. Manage. Sci. 62, 624-636.

Lun, R., Lee, K., De Marco, L., Nalewajko, C., Mackay, D., 1998. A model of the fate of polycyclic aromatic hydrocarbons in the Saguenay Fjord, Canada. Environ. Toxicol. Chem. 17, 333-341.

Mackay, D., 2001. Multimedia Environmental Models: The Fugacity Approach. Lewis Publishers, Boca Raton, FL, USA, p 261.

Mackay, D., Joy, M., Paterson, S., 1983. A quantitative water, air, sediment interaction (QWASI) fugacity model for describing the fate of chemicals in lakes. Chemosphere 12, 981-997.

Mackay, D., Sang, S., Vlahos, P., Diamond, M., Gobas, F., Dolan, D., 1994. A rate constant model of chemical dynamics in a lake ecosystem: PCBs in Lake Ontario. J. Great Lakes Res. 20, 625-642.

Mackay, D., Di Guardo, A., Paterson, S., Kicsi, G., Cowan, C.E., 1996a. Assessing the fate of new and existing chemicals: a five stage process. Environ. Toxicol. Chem. 15, 1618-1626.

Mackay, D., Di Guardo, A., Paterson, S., Cowan, C.E., 1996b. Evaluating the environmental fate of a variety of types of chemicals using the EQC model. Environ. Toxicol. Chem. 15, 1627-1637.

Mackay, D., Shiu, W.Y., Ma, K.C., 1997. In: Illustrated Handbook of Physical-Chemical Properties and Environmental Fate for Organic Chemicals, vol. V. Lewis Publishers, Boca Raton, FL, USA, p. 812.

MacLeod, M., Fraser, A.J., Mackay, D., 2002. Evaluating and expressing the propagation of uncertainty in chemical fate and bioaccumulation models. Environ. Toxicol. Chem. 21, 700-709.

Meyer, T., Wania, F., Breivik, K., 2005. Illustrating sensitivity and uncertainty in environmental fate model using partitioning maps. Environ. Sci. Technol. 39, 3186-3196.

Miao, Z., Cheplick, M.J., Williams, M.W., Trevisan, M., Padovani, L., Gennari, M., Ferrero, A., Vidotto, F., Capri, E., 2003. Simulating pesticide leaching and runoff in rice paddies with the RICEWQVADOFT model. J. Environ. Qual. 32, 2189-2199.

Oreskes, N., Shrader-Frechette, K., Belitz, K., 1994. Verification, validation, and confirmation of numerical models in the Earth Sciences. Science 263, 641-646.

Paraiba, L.C., Bru, R., Carrasco, J.M., 2002. Level IV fugacity model depending on temperature by a periodic control system. Ecol. Model. 147, 221-232.

Pereira, T., 2003. Impact of the use of pesticides in oriziculture ecosystems on the quality of surface waters. PhD thesis, Technical University of Lisbon, 394p.

Ross, L.J., Sava, R.J., 1986. Fate of thiobencarb and molinate in rice fields. J. Environ. Qual. 15, 220-225. 
Seiber, J.N., McChesney, M.M., Sanders, P.F., Woodrow, J.E., 1986. Models for assessing the volatilization of herbicides applied to flooded rice fields. Chemosphere 15, 127-138.

Silva, E., Batista, S., Viana, P., Antunes, P., Serôdio, L., Cardoso, A.T., Cerejeira, M.J., 2006. Pesticides and nitrates in groundwater from oriziculture areas of the 'Baixo Sado' (Portugal). Int. J. Environ. An. Ch. 86, 955-972.

Soderquist, C.J., Bowers, J.B., Crosby, D.G., 1977. Dissipation of molinate in a rice field. J. Agri. Food Chem. 25, 940-945.

Southwood, J.M., Muir, D.C.G., Mackay, D., 1999. Modelling agrochemical dissipation in surface microlayers following aerial deposition. Chemosphere 38, 121-141.

Tomlin, C.D.S., 1997. Pesticide Manual, 11th ed. British Crop Protection Council Surrey, UK.

Vidotto, F., Ferrero, A., Bertoia, O., Gennari, M., Cagnetti, A., 2004. Dissipation of pretilachlor in paddy water and sediment. Agronomie $24,473-479$.

$\mathrm{Vu}, \mathrm{S}$.H., Ishihara, S., Watanabe, H., 2006. Exposure risk assessment and evaluation of best management practices of pesticide runoff from paddy fields into rivers. Part I. Multi-scale paddy watershed monitoring. Pest. Manag. Sci. 62, 1193-1206.

Watanabe, H., Takagi, K., 2000a. A simulation model for predicting pesticide concentrations in paddy water and surface soil. 1. Model development. Environ. Technol. 21, 1379-1391.

Watanabe, H., Takagi, K., 2000b. A simulation model for predicting pesticide concentrations in paddy water and surface soil. 2. Model validation and application. Environ. Technol. 21, 1393-1404.

Watanabe, H., Takagi, K., Vu, S.H., 2006. Simulation of Mefenacet concentrations in paddy field by improved PCPF-1 model. Pest. Manag. Sci. 62, 20-29.

Watanabe, H., Nguyen, H.M., Komany, S., Vu, H.S., Thai, K.P., Tournebize, J., Ishihara, S., 2007. Effect of water management practice on pesticide behavior in paddy water. Agr. Water Manage. 88, 132140.

Wu, R.S., Sue, W.R., Chien, C.B., Chen, C.H., Chang, J.S., Lin, K.M., 2001. A simulation model for investigating the effects of rice paddy fields on the runoff system. Math. Comput. Model. 33, 649658 . 